\title{
ESTADO INMUNOLÓGICO DE TERNERAS Y TERNEROS DE LECHERÍA EN LA REGION HUETAR NORTE DE COSTA RICA. AÑO I ${ }^{1}$
}

\author{
Jeffry Sánchez-Salas ${ }^{2}$, Jorge Alberto Elizondo-Salazar ${ }^{2}$, Geovanny Arroyo-Quesada ${ }^{3}$
}

\begin{abstract}
RESUMEN
Estado inmunológico de terneras y terneros de lechería en la región Huetar Norte de Costa Rica. Año I. El objetivo del presente estudio fue realizar una caracterización del estado inmunológico de terneras y terneros de lechería en la región Huetar Norte de Costa Rica. Para fines del presente estudio, se consideró una falla en la adquisición de inmunidad pasiva cuando la concentración de PST fue menor a 5,5 $\mathrm{g} / \mathrm{dl}$. La concentración de PST varió entre 2,8 y $11,0 \mathrm{~g} / \mathrm{dl}$, con un contenido promedio general de $6,2 \mathrm{~g} / \mathrm{dl}$. De todos los animales evaluados un $31,8 \%$ presentaron niveles inadecuados de inmunidad. Cuando se considera el sexo de la cría, el $31,4 \%$ de las hembras y el 35,3\% de los machos obtuvieron niveles inadecuados de inmunidad y la concentración de PST presentó una diferencia estadísticamente significativa para hembras y machos (6,2 y 5,9 g/dl, respectivamente). Los animales provenientes del cruce Holstein $\mathrm{x}$ Jersey obtuvieron una concentración significativamente mayor a los de la raza Holstein. Las crías de novillas de primer parto presentaron concentraciones de PST de $6,3 \mathrm{~g} / \mathrm{dl}$ y por ende la menor proporción de terneros con niveles inadecuados de inmunidad. La concentración de PST no varió significativamente entre los terneros que permanecieron con la madre y los que fueron alimentados con chupón; sin embargo, la proporción de animales con niveles inadecuados de inmunidad fue mayor cuando éstos permanecieron con la madre $(34,1 \%$ vs. $29,3 \%$ ). Es necesario establecer prácticas de manejo del calostro que permitan minimizar el riesgo de terneros con una transferencia de inmunidad pasiva inadecuada en hatos lecheros de la región Huetar Norte de Costa Rica.
\end{abstract} nas, inmunidad pasiva, ganado de leche.

\begin{abstract}
Immune status of dairy calves in the Northern Plains of Costa Rica. Year I. The objective of this study was to characterize the immune status of dairy calves in the Northern Plains of Costa Rica. For the purpose of this study, failure of passive immunity was considered when TSP concentration was less than $5.5 \mathrm{~g} / \mathrm{dl}$. TSP concentration ranged from 2.8 to 11.0 , with an overall mean of $6.2 \mathrm{~g} / \mathrm{dl}$. Of all the animals evaluated, $31.8 \%$ had failure of passive transfer. When considering sex of the calves, $31.4 \%$ of females and $25.3 \%$ of males failed to obtain adequate levels of immunity and concentration of TSP showed significant differences $(6.2$ vs. $5.9 \mathrm{~g} / \mathrm{dl}$, respectively). Calves born to Holstein x Jersey crosses had significant higher TSP concentrations than calves born to Holstein dams. When considering calving of the dam, offsprings born to first time heifers TSP concentrations of $6.3 \mathrm{~g} / \mathrm{dl}$ and showed the lowest percentage of animals with inadequate transfer of immunity. TSP showed no significant differences for method of colostrum feeding; however, calves that suckled colostrum showed a higher proportion of animals with inadequate passive transfer when compared to calves that received colostrum by bottle (34.1 vs. $29.3 \%$ ). Colostrum management practices should be placed in order to minimize the risk of failure of passive transfer in dairy herds in the Northern Plains of Costa Rica.
\end{abstract}

Key words: total serum protein, immunoglobulins, passive immunity, dairy cattle.

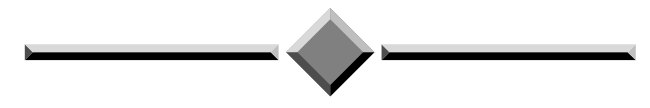

\footnotetext{
Recibido: 20 de febrero, 2012. Aceptado: 10 de octubre, 2012. Inscrito en la Vicerrectoría de Investigación, Proyecto 737-A9-184, Universidad de Costa Rica.

2 Estación Experimental Alfredo Volio Mata, Facultad de Ciencias Agroalimentarias, Universidad de Costa Rica. Costa Rica. jeffry. sanchezsalas@gmail.com; jorge.elizondosalazar@ucr.ac.cr

3 Programa de Transferencia Tecnológica de la Cooperativa de Productores de Leche Dos Pinos R. L. Costa Rica. geovanny.arroyo@dospinos.com
} 


\section{INTRODUCCIÓN}

A lo largo de muchos años, se ha documentado que los terneros de lechería dependen del traspaso de las inmunoglobulinas de la madre presentes en el calostro, proceso conocido como transferencia de inmunidad pasiva (TIP), el cual es crítico para la protección contra enfermedades infecciosas y la supervivencia, ya que el sistema inmune del ternero recién nacido es inmaduro e incapaz de producir suficientes inmunoglobulinas pues la placenta impide su transferencia al feto previo al nacimiento (Sasaki et al. 1983, Nocek et al. 1984).

De acuerdo con Stott et al. (1979abc), los factores que afectan el éxito o el fracaso de la TIP son básicamente el periodo de tiempo que transcurre entre el nacimiento y el suministro de calostro, así como la concentración de inmunoglobulinas y la cantidad consumida. No obstante, otros factores como la edad de la madre, la raza y el método de alimentación del calostro pueden también afectar el estado inmunológico de los terneros (Weaver et al. 2000).

Se han evaluado varios métodos para determinar con precisión el estado de la TIP en terneros. Estos métodos incluyen la medición directa de inmunoglobulinas (Igs) séricas por medio de la inmunodifusión radial u otras pruebas de ELISA (Filteau et al. 2003). También existen otros métodos indirectos para estimar la concentración de Igs como la medición de las proteínas totales en suero por refractometría, ya que durante la primera semana de vida, los mayores constituyentes de las proteínas séricas totales son las inmunoglobulinas provenientes del calostro (Wallace et al. 2006, Trotz-Williams et al. 2008). Weaver et al. (2000) destacan que este último método es una prueba de detección confiable para evaluar la TIP, dado que presenta una sensibilidad mayor al $94 \%$.

Diversas investigaciones han demostrado que las inmunoglobulinas del calostro adquiridas por las terneras después del nacimiento pueden tener un efecto sobre el crecimiento y la producción subsecuente (Denise et al. 1989, Faber et al. 2005, Berge et al. 2009). A pesar de conocer su importancia, en Costa Rica no existen estudios científicos concernientes al estado inmunológico de las terneras de lechería. Por esta razón, el objetivo del presente estudio fue realizar una caracterización del estado inmunológico de terneras y terneros de lechería en la región Huetar Norte de Costa Rica.

\section{MATERIALES Y MÉTODOS}

\section{Toma de muestras y evaluación de la transferencia de inmunidad pasiva}

Los datos presentados en este estudio corresponden a medidas de proteína sérica total obtenidas durante el periodo comprendido entre agosto y noviembre del 2010 en 57 fincas lecheras de la región Huetar Norte de Costa Rica. En dicho lapso de tiempo, las fincas fueron visitadas semanalmente y se tomaron muestras de sangre por venopunción yugular con el sistema Vacutainer® de tubos al vacío sin anticoagulante (tapa roja) en 506 terneros (455 hembras y 51 machos) con edades entre 1 y 7 días de nacidos.

Debido a que las fincas presentan diferencias en cuanto al manejo que se le da a los recién nacidos, para efecto del análisis de datos los terneros se dividieron en dos categorías, a saber: aquellos que consumieron calostro por amamantamiento directo de la madre (267 animales) y los que consumieron calostro por medio de chupón (239), donde estos últimos son separados de sus madres inmediatamente después del parto para que no ingieran calostro directamente de ellas.

No existió una metodología para la escogencia de las fincas, prácticamente cualquier lechería que estuviera dispuesta a permitir el sangrado de los animales en la zona de estudio se tomó en cuenta. Las lecherías son especializadas, es decir el ordeño se hace de forma mecánica en salas de ordeño. Las razas de las vacas se clasificaron en Holstein, Jersey, cruce Holstein-Jersey $(\mathrm{H} x \mathrm{~J})$ y otras (para cualquier raza que no se contempla en ninguna categoría de las anteriores). El tamaño de los hatos osciló entre 20 y 200 vacas en ordeño. En general, todos los animales en ordeño se encontraban bajo sistemas de pastoreo continuo.

Las muestras de sangre se manejaron de acuerdo al procedimiento descrito por Johnson et al. (2007) donde las muestras fueron refrigeradas durante la noche a $4^{\circ} \mathrm{C}$, posteriormente se centrifugaron a 3000 rpm durante 15 minutos para separar la fracción sérica. En seguida, la concentración de proteína sérica total (PST) se determinó utilizando un refractómetro de mano (Atago Master-Sur/Na, Bellevue, WA). Donovan et al. (1998) han establecido que las terneras presentan una falla en la adquisición de inmunidad pasiva cuando la concentración de PST es menor a 5,2 g/dl; sin embargo, otros autores consideran que estas deben 
presentar concentraciones mayores a 6,0 g/dl (Davis y Drackley 1998), por lo tanto, para fines del presente estudio, se consideró una falla en la adquisición de inmunidad pasiva cuando la concentración de PST fue menor a $5,5 \mathrm{~g} / \mathrm{dl}$.

\section{Análisis estadístico}

Para analizar los datos estadísticamente, además de agrupar a los recién nacidos por método de alimentación de calostro, también se agruparon por sexo, raza y número de parto de la madre.

Los datos se analizaron por medio del procedimiento MIXED de SAS (SAS Institute 2004) para determinar la significancia de los efectos del sexo y la raza de la cría, así como el número de lactancia de la madre y el método de alimentación del calostro, donde el animal se consideró como la variable aleatoria. La comparación entre medias se realizó mediante la prueba de Waller-Duncan $(\mathrm{P}<0,05)$. Asimismo, se generó estadística descriptiva para determinar la proporción de animales con una TIP inadecuada según el número de lactancia de la madre y el sexo de la cría.

\section{RESULTADOS Y DISCUSIÓN}

La concentración de PST en los 507 animales muestreados con edades entre 1 y 7 días de nacidos osciló entre 2,8 y $11,0 \mathrm{~g} / \mathrm{dl}$, con un promedio general de $6,2 \mathrm{~g} / \mathrm{dl}$. De todos los animales evaluados un $31,8 \%$ (161/506) presentó niveles inadecuados de inmunidad.

Este valor se asemeja a la media de $6,3 \mathrm{~g} / \mathrm{dl}$ de PST y al 37,1\% de terneros con una TIP inadecuada determinado por Trotz-Williams et al. (2008) en terneros de fincas lecheras canadienses. Sin embargo, dicha proporción puede considerarse elevado con respecto al 19,2\% reportado por Beam et al. (2009) en fincas lecheras en los Estados Unidos.

Los resultados obtenidos en el presente trabajo, son algo desalentadores, pues prácticamente indican que cuatro de cada diez terneros no adquieren una adecuada inmunidad pasiva. Esto es de suma importancia, ya que una baja concentración de Igs en el suero sanguíneo de las terneras está directamente relacionada con un aumento en la incidencia de enfermedades y muerte (Nocek et al. 1984, Hancock 1985, Robinson et al. 1988).
La literatura provee abundante información respecto a los factores que afectan la concentración sérica de Igs en terneras, siendo los más importantes la edad de la ternera en la que se le ofrece la primera toma de calostro y la masa de Igs ingerida, que a su vez está determinada por el volumen de calostro ofrecido y la concentración de Igs en el mismo (Elizondo-Salazar 2007). Con base en estos factores, los productores deben doblar esfuerzos para asegurar una adecuada transferencia de inmunidad materna a los recién nacidos.

\section{Sexo de la cría}

$\mathrm{Al}$ analizar la concentración de PST de acuerdo al sexo de la cría, se determinó que el 31,4\% (143/455) de las hembras y el 35,3\% (18/51) de los machos obtuvieron niveles inadecuados de inmunidad y la concentración promedio de PST presentó una diferencia estadísticamente significativa $(\mathrm{P}<0,05)$ para hembras y machos (6,2 y $5,9 \mathrm{~g} / \mathrm{dl}$, respectivamente). Al respecto, un estudio realizado por Ibrahim y Lemma (2009) determinó que el contenido de PST difirió significativamente entre hembras $(6,8 \mathrm{~g} / \mathrm{dl})$ y machos $(6,4 \mathrm{~g} / \mathrm{dl})$.

Es común encontrar diferencias de este tipo pues varias investigaciones indican que el sexo de la cría tiene una influencia en la TIP, donde por lo general los machos presentan menores concentraciones de PST con respecto a las hembras, debido a su mayor tamaño al nacimiento y por ende un mayor volumen de plasma sanguíneo que afecta la concentración de proteínas (Quigley et al. 1998, Quigley y Drewry 1998). También existe un factor de manejo que tiene que ver con la negligencia de no dar calostro a los machos u ofrecerles calostro de baja calidad, pues en la mayoría de los casos, son vendidos a las pocas horas de nacidos.

\section{Raza de la cría}

Cuando se evaluaron los datos considerando la raza de la cría, se pudo determinar que ésta influyó significativamente sobre la concentración de PST en los terneros evaluados. Se pudo observar que los animales provenientes del cruce Holstein x Jersey obtuvieron una concentración significativamente mayor a los de la raza Holstein, mientras que los terneros nacidos de vacas de la raza Jersey o de otras razas no difirieron significativamente del cruce Holstein x Jersey ni de la raza Holstein (Cuadro 1). 
Cuadro 1. Efecto de la raza de la cría sobre el contenido de proteína sérica total (PST) en 506 terneros entre uno y siete días de edad en 57 fincas lecheras de la región Huetar Norte de Costa Rica, 2010.

\begin{tabular}{lrcc}
\hline Raza & \multicolumn{1}{c}{$\mathbf{n}$} & PST $(\mathbf{g} / \mathbf{d l})$ & DE \\
\hline Holstein & 228 & $6,0 \mathrm{~b}$ & 1,3 \\
Holstein x Jersey & 73 & $6,5 \mathrm{a}$ & 1,5 \\
Jersey & 180 & $6,3 \mathrm{ab}$ & 1,5 \\
Otra & 25 & $6,3 \mathrm{ab}$ & 1,4 \\
\hline
\end{tabular}

$\mathrm{n}=$ Número de animales, PST $=$ Proteína sérica total, DE $=$ Desviación estándar.

Diferente letra en una misma columna difieren estadísticamente, $\mathrm{P}<0,05$.

Una de las razones que podrían explicar esta situación y que sin embargo no fue parte del presente estudio, tiene que ver con el tamaño de la cría al nacimiento, pues al igual que como pudo ocurrir con los machos, los neonatos de la raza Holstein son generalmente de mayor tamaño que las crías de las otras razas y por lo tanto pueden presentar más volumen de plasma sanguíneo, lo que implica que requieran de un mayor consumo de Igs para presentar un estado adecuado de inmunidad pasiva, mientras que animales de razas o cruces más pequeños pueden alcanzar dicho estado con un consumo menor de anticuerpos.

Por su parte, Muller y Ellinger (1981) encontraron que la raza es un factor que afecta el contenido de inmunoglobulinas en el calostro. Dichos autores reportaron concentraciones de 80,$8 ; 65,7 ; 90,4$ y 55,9 $\mathrm{g} / \mathrm{l}$ de inmunoglobulinas en el calostro de vacas de la raza Ayrshire, Pardo suizo, Jersey y Holstein, respectivamente. Por esta razón, los terneros nacidos de vacas Holstein, podrían adicionalmente estar consumiendo una menor cantidad de inmunoglobulinas con respecto a las otras razas.

\section{Número de partos de la madre}

Algunos autores han indicado que el número de parto de la madre es un factor asociado al contenido de inmunoglobulinas en el calostro, mostrando que el de las novillas de primer parto presentan una concentración de inmunoglobulinas considerablemente menor que el de vacas con tres o más lactancias y que a su vez dicha concentración se incrementa conforme aumenta el número de lactancias (Moore et al. 2005, Gulliksen et al. 2008, Kehoe et al. 2011).

Dicho aspecto podría eventualmente afectar la concentración de PST en las crías. Sin embargo, el número de parto no afectó significativamente esta variable en el presente estudio. Las crías de novillas de primer parto presentaron concentraciones de PST de $6,3 \mathrm{~g} / \mathrm{dl}$ y la menor proporción de terneros con niveles inadecuados de inmunidad (26,5\%) mientras que las crías de vacas con 5 partos o más exhibieron menores contenidos de PST $(6,1 \mathrm{~g} / \mathrm{dl})$ y una proporción de $34,5 \%$ de terneros con niveles inadecuados de inmunidad (Figura 1).

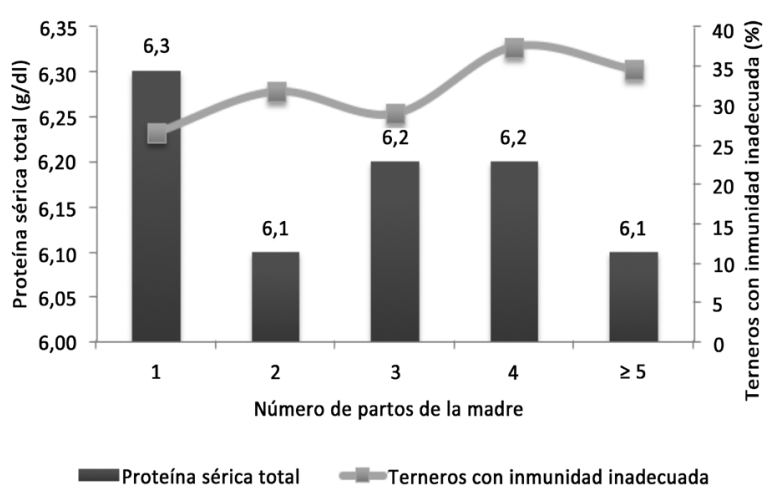

Figura 1. Efecto del número de partos de la madre sobre la concentración de proteína sérica total (PST) y la proporción de animales con inmunidad adecuada en 506 terneros entre uno y siete días de edad en 57 fincas lecheras de la región Huetar Norte de Costa Rica, 2010.

\section{Método de alimentación del calostro}

La concentración de PST no varió significativamente entre los terneros que permanecieron con la madre y los que fueron alimentados con chupón (Cuadro 2). Aún así, la proporción de animales con niveles inadecuados de inmunidad fue mayor cuando 
Cuadro 2. Efecto del método de alimentación del calostro sobre el contenido de proteína sérica total (PST) en 506 terneros entre uno y siete días de edad en 57 fincas lecheras de la región Huetar Norte de Costa Rica, 2010.

\begin{tabular}{lccc}
\hline $\begin{array}{l}\text { Método de } \\
\text { alimentación }\end{array}$ & $\mathbf{n}$ & PST (g/dl) & DE \\
\hline Amamantamiento & 267 & 6,1 & 1,5 \\
Chupón & 239 & 6,3 & 1,3 \\
\hline
\end{tabular}

n= Número de animales, PST $=$ Proteína sérica total, DE $=$ Desviación estándar.

éstos permanecieron con la madre (34,1\% vs. $29,3 \%)$, situación que pudo deberse a que los terneros que permanecieron con la madre pudieron haber consumido una menor cantidad de calostro y a una edad mayor que los terneros alimentados con chupón.

Dichas circunstancias ocasionan una pobre absorción de inmunoglobulinas y esta situación ha sido comprobada por algunos autores. Besser et al. (1991) y Quigley et al.(1995) demostraron en un experimento que los terneros que permanecieron con la madre después del nacimiento presentaron un menor contenido sérico de inmunoglobulinas en comparación con los que se les ofreció calostro por medio de chupón.

Entre tanto, se encontró un efecto significativo entre el número de parto de la madre y el método de alimentación del calostro. En este sentido, cuando las crías mamaron calostro de sus madres, la concentración de PST de las crías nacidas de novillas de primer parto fue mayor en comparación con las de vacas con cinco o más partos (Cuadro 3). Sin embargo, este efecto no se presentó en los animales que se alimentaron por medio de chupón.

Esta diferencia podría responder a un mayor desarrollo de la glándula mamaria o a una ubre colgante en las vacas adultas que limite la accesibilidad de los animales, por lo que se les dificulta la ingesta de calostro. Caso contrario sucede con los que se les ofreció el calostro por medio de chupón.

Para concluir, los resultados obtenidos en el presente estudio indican que es necesario establecer prácticas de manejo del calostro, que permitan minimizar el riesgo de terneros con una inadecuada transferencia de inmunidad pasiva en hatos lecheros de la región Huetar Norte de Costa Rica.

Los resultados de proteína sérica total (PST) obtenidos por refractometría en 506 terneros de 57 fincas lecheras de la región Huetar Norte de Costa Rica, indican que el 31,8\% de los animales obtuvieron una inmunidad pasiva inadecuada. Se encontró una asociación significativa entre la concentración de PST y la raza de las crías, así como entre el método de alimentación del calostro y el número de parto de la madre. Es necesario establecer prácticas de manejo de calostro que permitan minimizar el riesgo de terneros con una transferencia de inmunidad pasiva inadecuada en hatos lecheros de la región Huetar Norte de Costa Rica.

Cuadro 3. Efecto del número de parto de la madre y el método de alimentación del calostro sobre la concentración de proteína sérica total (PST) en 506 terneros entre uno y siete días de edad en 57 fincas lecheras de la región Huetar Norte de Costa Rica, 2010.

\begin{tabular}{ccccccccc}
\hline \multirow{2}{*}{ Parto } & \multicolumn{3}{c}{ Amamantamiento } & & \multicolumn{3}{c}{ Chupón } \\
\cline { 2 - 4 } \cline { 6 - 8 } & $\mathbf{n}$ & PST $(\mathbf{g} / \mathbf{d l})$ & $\mathbf{D E}$ & & $\mathbf{n}$ & PST (g/dl) & DE \\
\hline 1 & 39 & $6,6 \mathrm{a}$ & 1,3 & & 59 & 6,2 & 1,3 \\
2 & 74 & $6,1 \mathrm{ab}$ & 1,5 & & 49 & 6,1 & 1,4 \\
3 & 41 & $6,2 \mathrm{ab}$ & 1,5 & & 42 & 6,2 & 1,2 \\
4 & 49 & $5,9 \mathrm{ab}$ & 1,5 & & 34 & 6,5 & 1,5 \\
$\geq 5$ & 64 & $5,7 \mathrm{~b}$ & 1,4 & & 55 & 6,5 & 1,4 \\
\hline
\end{tabular}

n= Número de animales, PST= Proteína sérica total, DE= Desviación estándar.

Diferente letra en una misma columna difieren estadísticamente, $\mathrm{P}<0,05$. 


\section{AGRADECIMIENTOS}

Los autores desean expresar su más sincero agradecimiento al Programa de Transferencia Tecnológica de la Cooperativa de Productores de Leche Dos Pinos R.L. por la colaboración brindada durante la ejecución de la presente investigación. El agradecimiento es igualmente extensivo a los amables dueños de las fincas y a sus gentiles colaboradores.

\section{LITERATURA CITADA}

Beam, AL; Lombard, JE; Kopral, CA; Garber, LP; Winter, AL; Hicks, JA; Schlater, JL. 2009. Prevalence of failure of passive transfer of immunity in newborn heifer calves and associated management practices on US dairy operations. J. Dairy Sci. 92: 3973-3980.

Berge, ACB; Besser, TE; Moore, DA; Sischo, WM. 2009. Evaluation of the effects of oral colostrums supplementation during the first fourteen days on the health and performance of preweaned calves. J. Dairy Sci. 92: 286-295.

Besser, TE; Gay, CC; Pritchett, L. 1991. Comparison of three methods of feeding colostrums to dairy calves. J. Am. Vet. Med. Assoc. 198: 419-422.

Davis, CL; Drackley, JK. 1998. The development, nutrition, and management of the young calf. Iowa State University Press, Ames, Iowa. 329 p.

Denise, SK; Robison, JD; Stott, GH; Armstrong, DV. 1989. Effects of passive immunity on subsequent production in dairy heifers. J. Dairy Sci. 72:552-554.

Donovan, GA; Dahoo, IR; Montgomery, DM; Bennett, FL. 1998. Associations between passive transfer immunity and morbidity and mortality in dairy heifers in Florida, USA. Prevent. Vet. Med. 34:31-46.

Elizondo-Salazar, JA. 2007. Alimentación y manejo del calostro en el ganado de leche. Agronomía Mesoamericana. 18(2):271-281.

Faber, SN; Faber, NE; Mccauley, TC; Ax, RL. 2005. Effects of colostrum ingestion on lactational performance. The Professional Animal Scientist 21(5):420-425.

Filteau, V; Bouchard, E; Fecteau, G; Dutil, L; Dutremblay, D. 2003. Health status and risk factors associated with failure of passive transfer of immunity in newborn beef calves in Quebec. Can. Vet. J. 44:907-913.

Gulliksen, SM; Lie, KI; Sølverød, L; Østerås, O. 2008. Risk factors associated with colostrums quality in Norwegian dairy cows. J. Dairy Sci. 91:704-712.
Hancock, DD. 1985. Assessing efficiency of passive immune transfer in dairy herds. J. Dairy Sci. 68:163-183.

Ibrahim, A; Lemma, A. 2009. Relationships between serum protein concentration and passive transfer of immunity, morbidity and mortality of dairy calves in market oriented urban dairy farms. Revue Méd. Vét. 160 (89):394-399.

Johnson, JL; Godden, SM; Molitor, T; Ames, T; Hagman, D. 2007. Effects of feeding heat-treated colostrum on passive transfer of immune and nutritional parameters in neonatal dairy calves. J. Dairy Sci. 90:5189-5198.

Kehoe, SI; Heinrichs, AJ; Moody, ML; Jones, CM; Long, MR. 2011. Comparison of immunoglobulin G concentrations in primiparous and multiparous bovine colostrum. The Professional Animal Scientist 27 (3): 176-180.

Moore, M; Tyler, JW; Chigerwe, M; Dawes, ME; Middleton, JR. 2005. Effect of delayed colostrums collection on colostral IgG concentration in dairy cows. J. Am. Vet. Med. Assoc. 226:1375-1377.

Muller, LD; Ellinger, DK. 1981. Colostral immunoglobulin concentrations among breeds of dairy cattle. J. Dairy Sci. 64: 1727-1730.

Nocek, JE; Braund, DG; Warner, RG. 1984. Influence of neonatal colostrums administration, immunoglobulin, and continued feeding of colostrums on calf gain health, serum protein. J. Dairy Sci. 67:319-333.

Quigley, JD; Drewry, JJ. 1998. Nutrient and immunity transfer from cow to calf pre- and postcalving. J. Dairy Sci. 81: 2779-2790

Quigley, JD; Drewry, JJ; Martin, KR. 1998. Estimation of plasma volume in Holstein and Jersey calves. J. Dairy Sci. 81: 1308-1312.

Quigley, JD; Martin, KR; Bemis, DA; Potgieter, LND; Reinemeyer, CR; Rohrbach, BW; Dowlen, HH; Lamar, KC. 1995. Effects of housing and colostrums feeding on serum immunoglobulins, growth, and fecal scores of Jersey calves. J. Dairy Sci. 78:893-901.

Robison, JD; Stott, GH; DeNise, SK. 1988. Effects of passive immunity on growth and survival in the dairy heifer. J. Dairy Sci. 71(5):1283-1287.

Sasaki, M; Davis, CL; Larson, BL. 1983. Immunoglobulin IgG1 metabolism in new born calves. J. Dairy Sci. 60: 623-626.

SAS INSTITUTE. 2004. SAS/STAT 9.1 User`s guide. Version 9.1 ed. SAS Institute Inc., Cary, N.C. 5121 p.

Stott, GH, Marx, DB; Menefee, BE; Nightengale, GT. 1979a. Colostral immunoglobulin transfer in calves. I. Period of absorption. J. Dairy Sci. 62:1632-1638. 
Stott, GH; Marx, DB; Menefee, BE; Nightengale, GT. 1979b. Colostral immunoglobulin transfer in calves. II. The rate of absorption. J. Dairy Sci. 62: 17661773.

Stott, GH; Marx, DB; Menefee, BE; Nightengale, GT. 1979c. Colostral immunoglobulin transfer in calves. III. Amount of absorption. J. Dairy Sci. 62: 19021907.

Trotz-Williams, LA; Leslie, KE; Peregrine, AS. 2008. Passive immunity in Ontario dairy calves and investigation of its association with calf management practices. J. Dairy Sci. 91:3840-3849.

Wallace, MM; Jarvie, BD; Perkins, NR; Leslie, KE. 2006. A comparison of serum harvesting methods and type of refractometer for determining total solids to estimate failure of passive transfer in calves. Can. Vet. J. 47:573-575.

Weaver, DM; Tyler, JW; Vanmetre, DC; Hostetler, DE; Barrington, GM. 2000. Passive transfer of colostral immunoglobulins in calves. J. Vet. Intern. Med. 14: 569-577. 
